\title{
Reportear en el desamparo: Análisis de las medidas de protección a periodistas en México desde el contexto local
}

\author{
Reporting in the midst of helplessness: Analysis of the Mexican \\ journalists' protection measures from the local context
}

\author{
De León Vázquez, S. y González Macías, R. A. ${ }^{1}$ \\ Recibido: 26-03-2020 - Aceptado: 5-08-2020 \\ https://doi.org/10.26441/RC19.2-2020-A5
}

RESUMEN: En este trabajo se presenta un análisis formal de las leyes locales de protección a periodistas en México, el cual se contrastó con testimonios de los informadores recuperados a través de entrevistas semiestructuradas. Se parte de una reflexión teórica sobre el riesgo y el ejercicio periodístico en la actualidad y de la necesidad de su atención jurídica desde lo local. Posteriormente se practica un análisis formal argumentativo de los textos legislativos que se complementa con 55 entrevistas semiestructuradas realizadas a periodistas que ejercen su profesión en las localidades correspondientes, las cuales se levantaron entre febrero del 2017 y agosto del 2018. Los hallazgos muestran tres tipos de protección legal: social, civil y de la integridad física. Paradójicamente, la mayor parte de los periodistas expresan desconfianza sobre dicha protección con base en sus experiencias. La discusión final plantea la necesidad de mirar lo local para revisar la forma en la que se ofrecen garantías para el periodismo en el país más peligroso del mundo para ejercerlo.

Palabras clave: periodismo; legislación; protección; violencia; riesgo.

\begin{abstract}
The aim of this paper is to present a formal analysis of the local laws related to Mexican journalists' protection, and compare it with news workers' perceptions on this issue. The starting point is a theoretical discussion on the current risk of practicing journalism, and the need to provide local legal assistance. This is followed by an argumentative formal analysis of the local laws, complemented by a set of 55 semi-structured interviews with journalists from the same places, which were conducted between February 2017 and August 2018. The findings show three kinds of legal protection: social, civil, and physical. On the contrary, based upon their own experiences, reporters do not trust in those laws. The final argument is that the local context matters in order to understand how the protection measures operate in the most dangerous country in the world for journalism.
\end{abstract}

Keywords: journalism; legislation; protection; violence; risk.

\footnotetext{
${ }^{1}$ Salvador De León Vázquez es Doctor en Estudios Científico-Sociales por el Instituto Tecnológico y de Estudios Superiores de Occidente, Profesor-Investigador Titular del Departamento de Comunicación y Coordinador del Doctorado en Estudios Socioculturales de la Universidad Autónoma de Aguascalientes, México. salvador.deleonv@ edu.uaa.mx, https://orcid.org/0000-0002-7859-0480

Rubén Arnoldo González Macías es Doctor en Estudios de la Comunicación por la Universidad de Leeds, Profesor-Investigador del Instituto de Ciencias de Gobierno y Desarrollo Estratégico de la Benemérita Universidad Autónoma de Puebla, México, en donde coordina el Centro de Estudios en Comunicación Política. Es miembro del Sistema Nacional de Investigadores en el nivel de candidato. ruben.arnoldo@correo.buap.mx, https://orcid. org/0000-0002-6758-5328
} 


\section{Introducción}

El periodismo en México es una actividad de alto riesgo, específicamente el que tiene que ver con la cobertura del crimen organizado, la seguridad pública y la problemáticas sociales (CNDH, 2019; Trejo \& Trejo-Quintana, 2018; UNESCO, 2018). ${ }^{2}$ Académicos, periodistas y organizaciones no gubernamentales han señalado consistentemente que éste es el país más peligroso del mundo para quienes ejercen esta profesión (ver por ejemplo Hughes \& Márquez, 2017; Del Palacio, 2018; Artículo 19, 2019; CPJ, 2020). La cifra exacta de víctimas mortales en la última década oscila alrededor de un centenar, lo cual es excesivo para cualquier estado considerado como democrático, y -especialmente- que no se encuentre en guerra con otra nación (CPJ, 2020).

Ante esta situación, y como se discutirá a continuación, los estudios sobre este fenómeno se han enfocado en aspectos como el impacto de las agresiones en las rutinas periodísticas, en la cobertura del crimen organizado y/o temas de corrupción, y en la creación de organizaciones de periodistas, entre otros. Sin embargo, no se ha investigado el contenido de las leyes locales encaminadas a la protección de los informadores mexicanos en entornos de riesgo. En ese sentido, el objetivo de este artículo es analizar las legislaciones locales en esta materia, y contrastarlas con la percepción que de ellas tienen los periodistas. Es decir, el estudio implica -por una parte- un análisis de los documentos legislativos, y -por otra- una evaluación que los propios periodistas hacen de dichas leyes. Por lo tanto, la pregunta central que guía este trabajo es la siguiente: ¿Cuáles son las características de las legislaciones locales de protección a periodistas en México y cómo se vinculan con su realidad?

\section{Antecedentes}

La creciente violencia en contra de periodistas en México ha generado gran interés por indagar sobre sus causas desde diferentes vertientes. Existen diagnósticos desarrollados por organizaciones civiles como Artículo 19, la cual, en su informe del año 2018 ofrece datos recientes sobre las agresiones a periodistas, principalmente por parte de los agentes del Estado, la permanencia de la impunidad y la reafirmación de una geografía de la violencia instalada desde hace años en las regiones del Golfo de México, de la frontera norte y del sureste del país, principalmente (Ruelas et al., 2019). En ese mismo sentido apunta la Relatoría Especial para la Libertad de Expresión de la Comisión Interamericana de Derechos Humanos (2019), en cuyo último informe destaca que -lejos de disminuir- los asesinatos y agresiones contra los informadores mexicanos son constantes, al igual que la impunidad asociada con la falta de investigación judicial de los hechos y subsecuente condena de los perpetradores.

Otro tipo de organismos también vigilan y visibilizan la violencia contra periodistas en el país. Desde 1997 la Comisión Nacional de los Derechos Humanos (CNDH) cuenta con la Coordinación General del Programa de Agravios a Periodistas y Defensores Civiles de Derechos Humanos, desde la cual se generan informes y recomendaciones. El informe más reciente de la $\mathrm{CNDH}$ reconoce que si bien México es el país más peligroso para ejercer el periodismo, Veracruz es la entidad más riesgosa dentro del país (CNDH, 2019), pronunciamiento que coincide con las mediciones históricas del Índice de Desarrollo Democrático (Blomeier et al., 2019), los diagnósticos anuales de Artículo 19 (Ruelas et al., 2018, 2019) y el trabajo desarrollado por Del Palacio (2018).

\footnotetext{
${ }^{2}$ Si bien las víctimas mortales cubrían principalmente dichos temas, las agresiones contra periodistas no se circunscriben a alguna fuente o región en específico. Es decir, estudios más recientes han encontrado que hay una sensación generalizada de indefensión entre el gremio periodístico mexicano, independientemente de los temas que cubran, el medio para el que trabajen, o el lugar en donde vivan (González \& Reyna, 2019; González, 2020).
} 
La investigación académica sobre el tema ha aportado vetas de investigación relevantes para entender la problemática en su complejidad. Destacan dos trabajos colectivos: el coordinado por Del Palacio (2015) que presenta diferentes estudios que ponen el énfasis en las características locales del periodismo y la violencia; y el dirigido por Trejo \& Trejo-Quintana (2018) en donde se da cuenta del complejo fenómeno de la violencia contra la libertad de expresión, su desatención por parte del aparato estatal, las débiles regulaciones, la autogestión de los grupos independientes de periodistas, las recomendaciones de la $\mathrm{CNDH}$, entre otras cosas, incluye diversos análisis de la situación desde diferentes lugares de México por parte de expertos. El informe desarrollado por Brambila (2018) para el Colectivo de Análisis de la Seguridad con Democracia (CASEDE) ofrece datos detallados de las condiciones de la libertad de expresión y los riesgos que enfrenta en México, a la par que desarrolla una articulación entre los diagnósticos de los organismos previamente citados y la investigación académica.

La problemática, por ser multifactorial, ha permitido diferentes puntos analíticos de entrada que en su conjunto ayudan a tener un mapa más completo. Están los estudios que se han preguntado por la forma en la que los periodistas se organizan para enfrentar los riesgos a través de redes y colectivos debido a la débil protección que brinda el Estado (De León et al., 2018; Duarte, 2016; González de Bustamante, 2014). También hay investigaciones sobre las estrategias personales de los periodistas para la autoprotección (González \& Reyna, 2019; Relly \& González de Bustamante, 2014). Otros trabajos ahondan en aspectos estructurales asociados a la violencia como la fallida transición a la democracia, los poderes fácticos, las esferas extralegales, la precarización de la profesión periodística, la desatención del empresariado mediático, el clientelismo político, y un largo etcétera de condiciones que contribuyen a la vulnerabilidad de los periodistas en México (Cepeda, 2017; Merchant, 2017; Olvera \& Del Palacio, 2017; Reyna, 2018).

Retomando la preocupación por lo local, López (2020) cuestiona las líneas de investigación que reproducen un sesgo internacionalista en las relaciones entre las ONG de derechos humanos y los medios de comunicación, y llama a brindar atención a la manera en que ocurre esta relación en los contextos estatales, particularmente en aquellos donde hay exacerbación de la violencia contra periodistas. Hughes \& Márquez-Ramírez, (2017) aportan el repertorio de prácticas que los periodistas mexicanos realizan para reducir el riesgo, encontraron que las principales prácticas consisten en la autocensura, la censura del medio, abandonar el reporteo en la calle y reservar información delicada en la sala de redacción.

En la línea de investigación de la relación entre legislación y violencia contra periodistas, Hincapié \& López (2018) discuten que a pesar de que ha habido avances en la elaboración de leyes de rendición de cuentas y acceso a la información en México, cuestión que debería traer aparejada la protección del ejercicio periodístico como una forma de accountability, se ha generado un conjunto de mecanismos extralegales en un orden de facto que preserva la opacidad, la concentración y la coerción de las libertades ocasionando que el periodismo vigilante se convierta en objeto de persecución y violencia. Por su parte, Salazar (2018) demuestra, mediante el análisis de contenido, la influencia sobre la producción de las noticias en los estados cuyos códigos prevén sanciones al daño moral, bajo la hipótesis de que los funcionarios estatales lo utilizan para presionar a los periodistas sobre la información y su tratamiento.

No se encontraron investigaciones en las que se analicen las leyes locales de protección a periodistas. Existen estudios en los que se aborda el mecanismo de protección federal previsto por la ley, sobre todo de manera crítica y desde el punto de vista de los actores como en los trabajos de Trejo \& Trejo-Quintana (2018), González \& Reyna (2019) y Brambila (2018); pero no hay análisis de los contenidos de las leyes locales. Por ello, se juzga este trabajo como pertinente al atender un vacío de conocimiento necesario para contribuir al más completo entendimiento de la problemática. 


\section{La Protección a Periodistas y el Orden Jurídico Local}

La violencia contra los periodistas se ha consolidado como uno de los rasgos característicos del periodismo mexicano. Las agresiones en contra de los comunicadores son una violación a las garantías fundamentales de la expresión, vulneran el derecho a la información de la ciudadanía y, en ese sentido, minan los esfuerzos para la construcción de una sociedad democrática. En la actualidad, la mayor parte de los Estados democráticos tienen instrumentos para proteger y garantizar el acceso libre a la información, la libertad de expresión y la rendición de cuentas como derechos inalienables y básicos de sus ciudadanos.

Por mucho tiempo, una condición necesaria para poder llevar a cabo esta actividad [el periodismo] ha sido contar con medios de comunicación plurales e independientes del poder político, los que, a su vez, se han considerado requisitos mínimos indispensables de una vida democrática saludable. (Guerrero, 2016, p. 15)

Las condiciones para ese libre acceso a información periodística plural se encuentran en riesgo en México. De acuerdo con la UNESCO (2018), durante 2016 y 2017, México encabezó la lista de asesinatos de periodistas con 13 casos en cada año; la mayoría de ellos correspondieron a periodistas locales. La organización Artículo 19, por su parte, documentó 3,594 agresiones contra la prensa, 95 asesinatos de periodistas y 19 desapariciones en la República Mexicana durante los últimos doce años (Ruelas et al., 2019). La Fiscalía Especial para la Atención de Delitos cometidos contra la Libertad de Expresión (FEADLE, 2019) reconoce la existencia de 1,219 indagatorias iniciadas por periodistas del 2010 al 2019, y declara una eficacia resolutoria de 185 casos, es decir el $15.17 \%$, lo que habla de la impunidad en la que permanecen los perpetradores; de igual forma, tiene registro de 102 periodistas asesinados desde el año 2000 al 2019; señala además que de 2012 al 2019 la cantidad de 735 comunicadores se han acogido a las medidas de protección brindadas por el mecanismo previsto en la Ley Federal de Protección a Personas Defensoras de los Derechos Humanos y Periodistas promulgada en junio de 2012.

El informe más reciente de la organización Artículo 19 da cuenta de que, durante el año 2018, Veracruz fue el estado con mayor número de agresiones en contra de periodistas con 57 casos, seguido de Coahuila con 47, Puebla con 45, la Ciudad de México con 40 y Guerrero con 39, entre las más altas (Ruelas et al., 2019). Como puede observarse, el problema está agudizándose antes que resolverse, llegándose a considerar el año 2019 como el más violento de la historia reciente de México (Beauregard, 2020), que no es sino la escalada anual en la que, desde 2006, cada año se registra un incremento en la tasa de homicidios dolosos y desapariciones de personas asociados a la violencia (Franco, 2019).

Ante esta situación resulta pertinente preguntarse por las garantías legales que deberían proteger el ejercicio del periodismo en las entidades federativas con la finalidad de conocer las características de los instrumentos jurídicos a los que las víctimas pueden acceder para exigir protección y justicia.

¿Por qué es necesario que existan leyes locales para la protección a periodistas si ya se tiene una ley federal en la materia que es de observancia en todo el país? Calveiro (2012) sugiere que las violencias actuales son el resultado de una reorganización hegemónica a nivel planetario, donde México ha ocupado su lugar en la guerra contra el crimen organizado. Esta guerra, ha impactado a nivel local en el aumento del riesgo para los periodistas de sufrir agresiones de diversos tipos (Márquez, 2015). 
Tabla 1. Leyes federal y locales de protección a periodistas en México

\begin{tabular}{|c|c|c|}
\hline Entidad federativa & Nombre de la ley & Fecha de entrada en vigor \\
\hline Federal & $\begin{array}{l}\text { Ley de protección a personas defensoras de los derechos } \\
\text { humanos y periodistas }\end{array}$ & 25 de junio de 2012 \\
\hline Baja California & $\begin{array}{l}\text { Ley para el desarrollo y protección social de los periodistas del } \\
\text { estado de Baja California }\end{array}$ & 5 de octubre de 2012 \\
\hline Chiapas & $\begin{array}{l}\text { Ley de derechos para el ejercicio del periodismo en el estado } \\
\text { de Chiapas }\end{array}$ & 12 de septiembre de 2007 \\
\hline Ciudad de México & $\begin{array}{l}\text { Ley para la protección integral de personas defensoras de los } \\
\text { derechos humanos y periodistas de la Ciudad de México }\end{array}$ & 10 de agosto de 2015 \\
\hline Ciudad de México & Ley del secreto profesional del periodista & 7 de junio de 2006 \\
\hline Coahuila & $\begin{array}{l}\text { Ley para la protección de las y los periodistas para el estado } \\
\text { de Coahuila de Zaragoza }\end{array}$ & 18 de julio de 2014 \\
\hline Colima & $\begin{array}{l}\text { Ley para la protección integral del ejercicio periodístico para el } \\
\text { estado de Colima }\end{array}$ & 28 de julio de 2012 \\
\hline Durango & $\begin{array}{l}\text { Ley estatal para la protección de periodistas y personas defen- } \\
\text { soras de los derechos humanos }\end{array}$ & 25 de diciembre de 2014 \\
\hline Guanajuato & $\begin{array}{l}\text { Ley de protección de personas defensoras de derechos huma- } \\
\text { nos y periodistas del estado de Guanajuato }\end{array}$ & 26 de octubre de 2017 \\
\hline Guanajuato & $\begin{array}{l}\text { Ley del secreto profesional del periodista del estado de Gua- } \\
\text { najuato }\end{array}$ & 21 de noviembre de 2014 \\
\hline Guerrero & $\begin{array}{l}\text { Ley número } 463 \text { para el bienestar integral de los periodistas } \\
\text { del estado de Guerrero }\end{array}$ & 17 de mayo de 2002 \\
\hline Guerrero & $\begin{array}{l}\text { Ley número } 489 \text { para la protección de personas en situación } \\
\text { de riesgo del estado de Guerrero }\end{array}$ & 26 de agosto de 2014 \\
\hline Hidalgo & $\begin{array}{l}\text { Ley de protección a personas defensoras de los derechos } \\
\text { humanos y salvaguarda de los derechos para el ejercicio del } \\
\text { periodismo }\end{array}$ & 27 de agosto de 2012 \\
\hline Jalisco & $\begin{array}{l}\text { Ley para la protección de personas defensoras de los dere- } \\
\text { chos humanos y periodistas del estado de Jalisco }\end{array}$ & 17 de diciembre de 2016 \\
\hline Michoacán & $\begin{array}{l}\text { Ley para la protección de personas defensoras de los de- } \\
\text { rechos humanos y periodistas del estado de Michoacán de } \\
\text { Ocampo }\end{array}$ & 14 de agosto de 2018 \\
\hline Morelos & $\begin{array}{l}\text { Ley de protección a periodistas y defensores de derechos } \\
\text { humanos del estado de Morelos }\end{array}$ & 20 de agosto de 2018 \\
\hline Nayarit & $\begin{array}{l}\text { Ley de protección de personas defensoras de derechos huma- } \\
\text { nos y periodistas del estado de Nayarit }\end{array}$ & 27 de julio de 2017 \\
\hline Querétaro & $\begin{array}{l}\text { Ley que establece el secreto profesional periodístico en el } \\
\text { estado de Querétaro }\end{array}$ & 7 de julio de 2012 \\
\hline San Luis Potosí & $\begin{array}{l}\text { Ley de protección al ejercicio del periodismo del estado de } \\
\text { San Luis Potosí }\end{array}$ & 30 de abril de 2013 \\
\hline Sonora & $\begin{array}{l}\text { Ley que establece el secreto profesional periodístico en el } \\
\text { estado de Sonora }\end{array}$ & 28 de abril de 2011 \\
\hline Tamaulipas & $\begin{array}{l}\text { Ley para la protección de personas defensoras de los dere- } \\
\text { chos humanos y periodistas para el estado de Tamaulipas }\end{array}$ & 01 de diciembre de 2017 \\
\hline Veracruz & $\begin{array}{l}\text { Ley de la comisión estatal para la atención y protección de los } \\
\text { periodistas }\end{array}$ & 3 de diciembre de 2012 \\
\hline
\end{tabular}

Nota. La tabla procede de la revisión de los conjuntos legales de los 32 estados de México vigentes hasta diciembre de 2018 para identificar en cuáles existían leyes estatales de protección a periodistas. Fuente: elaboración propia.

En ese orden de ideas, Vado (2008) considera que el federalismo implica diferentes órdenes jurídicos, los cuales se pueden sintetizar en tres: comunidad jurídica total, comunidad jurídica federal y comunidad jurídica local. La importancia de las leyes locales radica en que expresan la comunidad legalmente organizada de las entidades subnacionales las cuales deben valorarse "como espacios de 
decisión jurídica mediante la adopción de soluciones particulares para problemas locales" (Vado, 2008, p. 228).

Por su parte, Kucsko-Stadlmayer (2017) plantea que el Derecho debe reconocerse como un orden social, y sus normas se refieren a fenómenos sociales del comportamiento humano reconocidos por los pueblos en determinadas épocas. En ese sentido, las normas jurídicas -dice el autor-regulan aquello que se considera valioso para la comunidad, y tienen naturaleza coactiva, pero consensada, para obligar a que sea respetado; son "actos coactivos de la comunidad socialmente organizados" (p. 229). Usando estos argumentos, podríamos considerar que las leyes locales constituyen una expresión del orden social local con vocación normativa, y dado que la violencia contra periodistas ocurre en los ámbitos locales cabe plantear la pregunta de investigación ¿Cuáles son las características de las legislaciones locales de protección a periodistas en México y cómo se vinculan con su realidad?

En México existen 22 leyes que protegen el ejercicio periodístico. Una de ellas es federal, las 21 restantes se distribuyen en 18 estados. La tabla 1 muestra las leyes por entidad federativa y la fecha de su promulgación. El supuesto es que estas leyes ofrecen una configuración particular de acuerdo con los asuntos de importancia local en la protección de los periodistas.

\section{Periodismo, Riesgo y Legislación: Fundamentos Teóricos}

En América Latina, el tránsito al postautoritarismo pasa en el periodismo por episodios de violencia contra la prensa, según lo considera Waisbord (2002), relacionados con la debilidad de los procesos de instauración de la democracia, generando así una tendencia en la que los medios y periodistas son blanco de ataques físicos a causa de las dificultades del gobierno para imponer el Estado de Derecho. A esto se agrega que durante el siglo XX se confeccionaron leyes por medio de las cuales el propio Estado ejercía controles sobre la prensa al representar ésta la arena central de la expresión pública y que, lejos de protegerla, la vulneraban. Así pues, este autor sugiere que la violencia física y la violencia judicial representan las principales condiciones de riesgo para el periodismo en el subcontinente.

El riesgo por las agresiones, como hemos visto, persiste y se incrementa. Pero en el terreno de lo legal están ocurriendo situaciones que es necesario estudiar. Santander (2014) observa que la formulación de leyes para normar los sistemas mediáticos en América Latina se ha convertido, en el siglo XXI, en un terreno de disputa en donde los Estados, la sociedad civil organizada y los empresarios de medios luchan por dominar la generación de leyes sobre el espacio mediático. La pugna principal es la de las formas capitalistas de organización de los medios contra posturas críticas provenientes de la izquierda latinoamericana.

Sin embargo, este nuevo interés por la regulación de los medios en América Latina ha sido impulsado por varias transformaciones como la reconfiguración del ámbito mediático debido a las innovaciones tecnológicas y, con ello, la transformación de las lógicas de la difusión, la puesta en crisis de los modelos de negocio, la pérdida de centralidad de los medios tradicionales, la precarización del trabajo periodístico, el clima de violencia, por citar algunas. Esto ha desembocado en nuevas leyes en las que "se reconocen 'otros ámbitos' de comunicación y se lleva a cabo la 'relocalización' del espacio comunicativo, con la entrada de nuevos y viejos actores, tradicionalmente excluidos" (Gómez \& Ramos-Martín, 2014, p. 487).

A pesar de este impulso legislativo, la mayor parte de los estudios sobre la violencia contra periodistas coinciden en señalar la reiterada desconfianza de los comunicadores hacia los actores institucionales y los mecanismos previstos por las leyes, debido a su baja eficacia (Cepeda, 2017; González \& Reyna, 2019; Hughes \& Márquez-Ramírez, 2017; Olvera \& Del Palacio, 2017). 
Un caso paradigmático fue el del fotoperiodista Rubén Espinosa quien, amenazado de muerte, solicitó la ayuda del mecanismo federal de protección por medio del cual fue reubicado de Veracruz a la Ciudad de México, en donde finalmente fue asesinado en el año 2015. Por situaciones como ésta, en las que los mecanismos de protección resultan inútiles debido a que la violencia se impone, los periodistas prefieren buscar formas extra-institucionales de protección personal, a partir de la creación de redes de solidaridad y apoyo, una forma de subpolítica (Beck, 2006) para encontrar soluciones a los problemas que el Estado no logra resolver, percibiéndose desatendidos por parte de las dos grandes estructuras que deberían protegerlos: el Estado y las empresas periodísticas (De León et al., 2018; González \& Reyna, 2019). Esta inoperancia ha generado fuertes críticas de parte de los periodistas que se perciben a sí mismos en total indefensión (Ramírez, 2018).

Las legislaciones de protección a periodistas operan en la dimensión jurídica. La mayor parte de los Estados democráticos no contemplan leyes especiales para protección de periodistas distintas a las que son de observancia para la población en su conjunto. En México, el alto número de agresiones a la prensa y los asesinatos de periodistas y activistas generó acciones de presión de parte de la sociedad civil organizada que llevó al gobierno federal a emitir la ley federal para protegerlos en 2012, y posteriormente fue replicada a nivel local en algunos estados de la república mexicana. Sin embargo, la violencia contra comunicadores constituye un fenómeno multidimensional. Por ello es necesario estudiar los alcances y límites de lo jurídico en relación con las otras dimensiones, en aras de encontrar formas articuladas de enfrentar la problemática para soluciones definitivas.

Sostenemos que hace falta una mejor comprensión de la naturaleza del régimen político, nacional y local, de los ciclos de desarrollo del crimen organizado en el territorio, así como de la estructura de los mercados mediáticos y de la precariedad de la inserción de los periodistas en éstos, para entender la mecánica de la violencia contra los periodistas. (Olvera \& Del Palacio, 2017, p. 18)

Ahora bien, aunque la violencia física -y particularmente el asesinato- representa la forma más evidente de riesgo, éste no se agota ahí. Otras formas de riesgo están asociadas a la degradación del entorno laboral de los periodistas en forma de procesos de precarización, individualización y desempleo (Reyna, 2018, 2019), así como el uso de mecanismos legales o de publicidad oficial como formas de presión para diferentes fines como revelar sus fuentes, limitar su acceso a espacios e información, controlar las líneas editoriales, censurar el escrutinio de figuras públicas alegando daño moral, situaciones que también pueden afectar su integridad física y/o psicológica, su estabilidad económica o el mantenimiento de su empleo (Hernández, 2016; Mellado, 2016). Es por eso que, en este trabajo, el reconocimiento de leyes de protección a periodistas se extiende de la protección contra las agresiones a la de sus derechos sociales y civiles, cuyo incumplimiento también es una forma de violencia, así reconocido por la Comisión Interamericana de Derechos Humanos (Botero, 2013). No es una decisión arbitraria, el propio corpus de las leyes estatales y las problemáticas que enfrentan los periodistas en México así lo sugieren.

Así pues, será necesario incorporar este trabajo al conjunto de los estudios que abordan la violencia contra periodistas, los cuales desarrollan sus aproximaciones desde diferentes puntos de entrada al análisis del fenómeno. Cada aportación suma elementos de explicación y permite avanzar en las acciones posibles para afrontarlo. Esta investigación sobre las legislaciones estatales de protección a periodistas requiere ser colocada en contexto, tanto empírico como teórico.

\section{Metodología}

Se estableció una estrategia metodológica que combina el análisis formal del contenido de las 21 leyes locales con entrevistas semiestructuradas a comunicadores de la mayoría de los estados 
correspondientes. El análisis formal "se relaciona fundamentalmente con la organización interna de las formas simbólicas, con sus rasgos, patrones y relaciones estructurales" (Thompson, 1998, p. 413). A su vez, hemos privilegiado la forma argumentativa del análisis formal, la cual tiene como objetivo reconocer y hacer explícitos los patrones de inferencia de un texto. El método consiste en "separar el corpus discursivo en conjuntos de enunciados o aseveraciones organizadas en torno a ciertos asuntos o temas, y trazar después relaciones existentes entre estos enunciados y asuntos" (Thompson, 1998, p. 419).

El análisis se llevó a cabo mediante una codificación fundamentada sobre los textos de las leyes, considerando los párrafos de los artículos legales como unidades de análisis. Para ello se utilizó el software Nvivo 12, generándose 20 categorías, las cuales se repartieron en tres dimensiones claramente definidas como se muestra en la tabla 2.

Tabla 2. Clasificación de categorías fundamentadas del análisis formal de leyes locales de protección a periodistas en México

\begin{tabular}{|c|c|}
\hline Dimensiones & Categorias \\
\hline 1. Protección de los periodistas ante el riesgo & $\begin{array}{l}\text { 1. Definición de periodista } \\
\text { 2. Colegiación de periodistas } \\
\text { 3. Derechos sociales de los periodistas } \\
\text { 4. Derechos civiles de los periodistas } \\
\text { 5. Riesgo, violencia y agresiones } \\
\text { 6. Medidas de protección a periodistas } \\
\text { 7. Protección de identidad y datos personales } \\
\text { 8. Capacitación y formación }\end{array}$ \\
\hline $\begin{array}{l}\text { 2. Organización administrativa para el } \\
\text { cumplimiento del objeto de la ley }\end{array}$ & $\begin{array}{l}\text { 9. Elaboración de padrones de periodistas } \\
\text { 10. Estudios, diagnósticos, evaluaciones e informes } \\
\text { 11. Fondos, presupuestos y fideicomisos } \\
\text { 12. Actores responsables de procesos } \\
\text { 13. Elaboración de políticas públicas } \\
\text { 14. Comités y organismos } \\
\text { 15. Acciones, técnicas, mecanismos y medidas }\end{array}$ \\
\hline 3. Acciones vinculatorias & $\begin{array}{l}\text { 16. Responsabilidad de empresarios y directivos } \\
\text { 17. Responsabilidad del Estado } \\
\text { 18. Situaciones de excepción } \\
\text { 19. Quejas, denuncias y sanciones } \\
\text { 20. Vínculos con otras leyes }\end{array}$ \\
\hline
\end{tabular}

Nota. Las categorías proceden de la codificación fundamentada del corpus compuesto por las 21 leyes locales de protección a periodistas identificadas en este estudio. Fuente: elaboración propia.

Las entrevistas semiestructuradas se utilizaron para conocer la evaluación de los periodistas respecto a las medidas de protección derivadas de las legislaciones federal y estatales. Esta parte del estudio se construye a partir de información brindada por periodistas de 13 de las 18 entidades que cuentan con una ley de este tipo. Cabe precisar que este material forma parte de un proyecto más amplio, cuyo objetivo general es el análisis del impacto individual, organizacional, y social de la violencia contra periodistas en México ${ }^{3}$.

Las entrevistas fueron realizadas entre febrero del 2017 y agosto del 2018 a 55 informantes. La distribución geográfica fue la siguiente: Baja California 9, Chiapas 3, Ciudad de México 4, Coahuila 3, Guanajuato 2, Guerrero 2, Jalisco 6, Michoacán 7, Morelos 1, San Luis Potosí 4,

\footnotetext{
${ }^{3}$ La pregunta específica que se utiliza para este artículo es “¿Cuál es su opinión de los mecanismos legales para la protección de periodistas con los que se cuenta en México?".
} 
Sonora 5, Tamaulipas 4, y Veracruz 54. La selección de entrevistados siguió la lógica de bola de nieve, puesto que fueron los mismos periodistas quienes recomendaron a otros colegas para participar en el estudio.

La selección de participantes fue determinada a partir de dos criterios: en primer lugar, debían ser periodistas en activo, ya fueran empleados de alguna redacción o freelancers. En segundo lugar, se requería que, en el momento de la entrevista, cubrieran -o hayan cubierto consistentemente- hard news, especialmente temas de delincuencia organizada o corrupción. No fue criterio de exclusión su rol (por ejemplo, reportero, editor, fotógrafo, camarógrafo, conductor), ni el tipo de medio para el que trabajaran (periódico, revista, radio, televisión, o portal de noticias). Se condujeron entrevistas con reporteros locales y corresponsales estatales de medios reconocidos a nivel regional y nacional.

Dada la sensibilidad de la información recabada, la identidad de los informantes es tratada de manera confidencial. Por lo tanto, cada alusión directa a la respuesta de uno de ellos está codificada con las siguientes claves: $E$ (entrevistado), abreviatura del estado de procedencia (por ejemplo, $B C$ para Baja California) y un número para su identificación en el análisis $(E B C 3)$.

\section{Resultados}

La tendencia de las agresiones a periodistas en México es alarmante. Con la finalidad de otorgar contexto a nuestro análisis presentaremos primero los datos de la organización PoliLat sobre el índice de desarrollo democrático en México. Uno de los elementos que forman parte de ese instrumento es el índice de la libertad de prensa, el cual pondera las condiciones para el ejercicio de una prensa libre y se obtiene de la percepción sobre la libertad de expresión de ciudadanos encuestados más la cantidad de periodistas víctimas de la violencia en cada estado (PoliLat, 2020). La tabla 3 muestra los resultados para los 32 estados la república.

El índice ha sido construido a partir de dos indicadores evaluados anualmente: la percepción de los ciudadanos respecto a la libertad de expresión y la cantidad de periodistas víctimas de la violencia en cada estado. El valor se obtiene asignando 10 puntos al valor más alto de la percepción ciudadana y 10 puntos al más bajo de violencia contra periodistas; se suman y se los divide entre dos. Luego se organizan considerando el valor más alto de la distribución, bajo la lógica de relevamiento empírico (PoliLat, s/f).

Se puede observar que algunos de los puntajes de los estados que cuentan con leyes de protección son muy bajos, particularmente en Veracruz que ha tenido la peor calificación en casi todos los años. También se identifican otros estados con baja calificación y en los que no se han generado instrumentos legales de este tipo como Oaxaca, Quintana Roo, Puebla y Sinaloa. La figura 1 permite visualizar las tendencias similares respecto al índice de libertad de prensa que presentan los 18 estados con legislación de protección a periodistas. En general, muestra una tendencia de caída entre 2010 y 2017 , siendo este último el año más crítico, y un repunte en 2018 y 2019.

\footnotetext{
${ }^{4}$ Puesto que el estudio original del que se desprenden las entrevistas no incluía algunas entidades aquí analizadas, no se cuenta con informantes de todos estados con legislación de protección a periodistas. No obstante, dada la amplitud de la muestra usada en este reporte, se considera que hay la suficiente representatividad en las respuestas. Por tanto, se puede inferir que la percepción de los periodistas en dichas entidades no debe desviarse significativamente de la del resto de sus colegas en el país.
} 
Tabla 3. Índice de la libertad de prensa en México, por entidad federativa

\begin{tabular}{|c|c|c|c|c|c|c|c|c|c|}
\hline $\begin{array}{l}\text { Entidad } \\
\text { Federativa }\end{array}$ & 2010 & 2011 & 2012 & 2013 & 2014 & 2015 & 2017 & 2018 & 2019 \\
\hline Aguascalientes & 9.755 & 9.225 & 9.873 & 7.803 & 8.748 & 8.357 & 2.545 & 8.357 & 7.726 \\
\hline B. California* & 6.469 & 5.504 & 5.204 & 6.032 & 5.588 & 6.462 & 2.584 & 6.462 & 8.569 \\
\hline Baja C. Sur & 7.203 & 5.194 & 9.367 & 9.283 & 9.591 & 7.602 & 2.345 & 7.602 & 9.387 \\
\hline Campeche & 7.448 & 7.907 & 6.973 & 7.167 & 8.006 & 9.367 & 2.687 & 9.367 & 6.636 \\
\hline Coahuila* & 3.671 & 4.109 & 3.045 & 9.312 & 9.228 & 6.462 & 2.403 & 6.462 & 4.014 \\
\hline Colima* & 8.182 & 9.225 & 8.738 & 6.762 & 7.148 & 5.195 & 2.724 & 5.195 & 8.762 \\
\hline Chiapas* & 5.734 & 2.248 & 3.557 & 6.462 & 6.845 & 6.973 & 3.203 & 6.973 & 6.691 \\
\hline Chihuahua & 3.531 & 0 & 1.14 & 7.235 & 8.045 & 7.471 & 4.391 & 7.471 & 8.206 \\
\hline Cd. México* & 5.734 & 2.481 & 2.412 & 2.43 & 2.144 & 0.891 & 3.202 & 0.891 & 4.609 \\
\hline Durango* & 5.734 & 8.14 & 5.955 & 6.384 & 7.434 & 7.597 & 3.149 & 7.597 & 10 \\
\hline Guanajuato* & 5.385 & 7.907 & 8.986 & 8.847 & 8.837 & 8.991 & 3.557 & 8.991 & 7.744 \\
\hline Guerrero* & 5 & 4.109 & 3.932 & 7.808 & 8.371 & 2.412 & 3.022 & 2.412 & 2.236 \\
\hline Hidalgo* & 8.182 & 8.682 & 7.602 & 8.434 & 8.602 & 10 & 3.175 & 10 & 7.803 \\
\hline Jalisco* & 7.448 & 4.419 & 7.597 & 7.36 & 8.243 & 9.873 & 2.646 & 9.873 & 6.124 \\
\hline México & 8.182 & 6.589 & 6.09 & 7.762 & 8.599 & 5.204 & 3.692 & 5.204 & 5.406 \\
\hline Michoacán* & 6.224 & 7.597 & 6.462 & 6.763 & 7.523 & 6.09 & 3.084 & 6.09 & 8.078 \\
\hline Morelos* & 8.427 & 4.651 & 7.471 & 7.258 & 7.299 & 5.833 & 3.196 & 5.833 & 9.021 \\
\hline Nayarit $^{*}$ & 8.182 & 7.364 & 9.118 & 7.474 & 8.181 & 8.986 & 2.798 & 8.986 & 8.633 \\
\hline Nuevo León & 7.203 & 5.969 & 7.09 & 7.444 & 7.785 & 7.09 & 3.607 & 7.09 & 8.204 \\
\hline Oaxaca & 1.084 & 4.109 & 0.891 & 3.444 & 3.354 & 3.045 & 3.989 & 3.045 & 5.716 \\
\hline Puebla & 6.224 & 6.512 & 5.955 & 6.31 & 6.632 & 3.425 & 4.362 & 3.425 & 3.874 \\
\hline Querétaro* & 8.427 & 7.907 & 6.973 & 10 & 10 & 3.932 & 4.739 & 3.932 & 9.674 \\
\hline Quintana Roo & 6.224 & 8.14 & 6.462 & 6.962 & 7.637 & 1.14 & 3.709 & 1.14 & 4.154 \\
\hline San Luis P.* & 10 & 6.047 & 8.991 & 7.798 & 8.366 & 6.842 & 4.566 & 6.842 & 8.222 \\
\hline Sinaloa & 4.266 & 4.651 & 3.425 & 7.252 & 7.802 & 3.557 & 6.098 & 3.557 & 6.023 \\
\hline Sonora* & 7.937 & 6.589 & 8.357 & 5.599 & 5.847 & 6.973 & 6.349 & 6.973 & 7.886 \\
\hline Tabasco & 7.203 & 7.054 & 6.842 & 8.472 & 9.129 & 5.955 & 5.847 & 5.955 & 7.107 \\
\hline Tamaulipas* & 6.469 & 3.566 & 5.195 & 5.289 & 5.924 & 5.955 & 5.946 & 5.955 & 6.116 \\
\hline Tlaxcala & 8.427 & 7.364 & 10 & 8.926 & 9.388 & 9.118 & 4.304 & 9.118 & 8.068 \\
\hline Veracruz ${ }^{*}$ & 0 & 4.884 & 0 & 0 & 0 & 0 & 3.132 & 0 & 0 \\
\hline Yucatán & 7.692 & 7.054 & 7.602 & 8.204 & 8.977 & 8.738 & 3.373 & 8.738 & 8.6 \\
\hline Zacatecas & 6.469 & 10 & 5.833 & 7.338 & 8.484 & 7.602 & 3.421 & 7.602 & 9.325 \\
\hline
\end{tabular}

Nota. La ponderación considera una calificación mínima de 0 y máxima de 10, otorgada a la peor y mejor entidad respectivamente de manera anual; el resto se distribuye entre esos rangos. Fuente: elaboración propia con datos de PoliLat (2020).

* Entidades con legislaciones locales de protección a periodistas.

** No se tiene registro de medición realizada por PoliLat para el año 2016. 
Figura 1. Histograma del índice de libertad de prensa en los estados con leyes de protección a periodistas

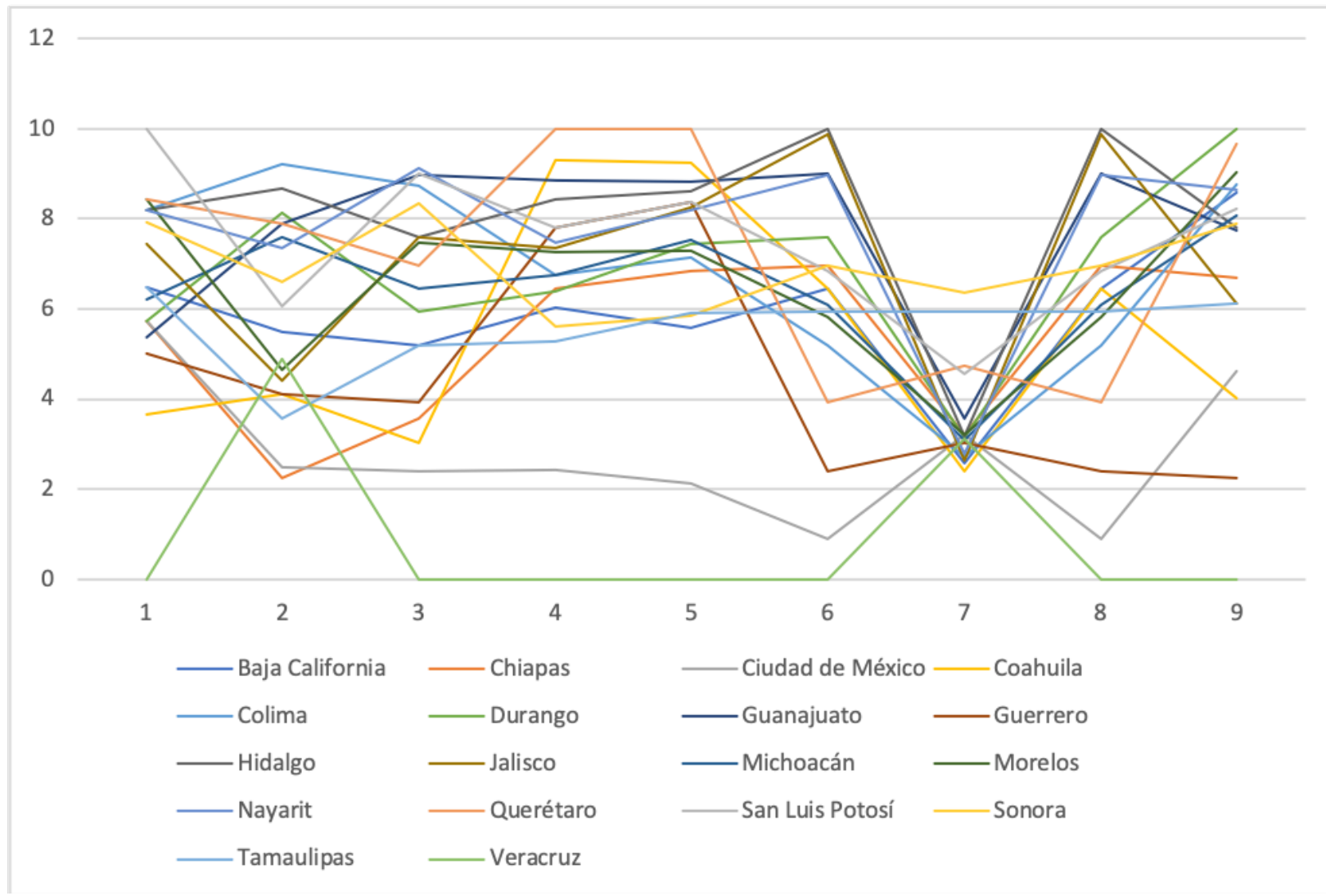

Nota. En la figura se aprecia el comportamiento histórico del índice de la libertad de prensa en los estados seleccionados, 2010-2019. No hay registro de medición para el año 2016. Fuente: elaboración propia con datos de PoliLat (2020).

\section{Tipología de las Leyes Locales de Protección a Periodistas}

En las 21 leyes analizadas existen tres diferentes concepciones de protección a periodistas. Es decir, no todas se enfocan en la violencia contra comunicadores. Las otras dos formas de protección consisten en el reconocimiento de los derechos sociales y el tutelaje de derechos civiles para el ejercicio del periodismo. La tabla 4 muestra la distribución de las leyes locales de acuerdo con el tipo de protección que norman.

Tabla 4. Distribución de estados por tipo de protección a periodistas que otorga la ley

\begin{tabular}{|c|c|}
\hline Tipo de Ley & Estados \\
\hline Protección contra violencia para periodistas & $\begin{array}{l}\text { Ciudad de México, Coahuila, Durango, Guanajuato, Guerrero, } \\
\text { Hidalgo, Jalisco, Michoacán, Morelos, Nayarit, Tamaulipas y Veracruz }\end{array}$ \\
\hline $\begin{array}{l}\text { Protección de derechos sociales de los } \\
\text { periodistas }\end{array}$ & Baja California y Guerrero \\
\hline $\begin{array}{l}\text { Protección de derechos civiles para el } \\
\text { ejercicio periodístico }\end{array}$ & $\begin{array}{l}\text { Chiapas, Ciudad de México, Colima, Guanajuato, Querétaro, San } \\
\text { Luis Potosí y Sonora }\end{array}$ \\
\hline
\end{tabular}

Nota. La tabla se refiere a las formas diferenciadas y específicas de protección. Fuente: elaboración propia.

Protección contra violencia a periodistas. Las leyes de este tipo se alinean con la ley federal. Estas leyes protegen a los periodistas y a los defensores de los derechos humanos o activistas. Se establecen comités y organismos encargados de ejecutar las acciones para proteger a los periodistas 
en riesgo y administrar los fondos y fideicomisos. Se consideran tres diferentes medidas para su puesta en acción: medidas preventivas, medidas de protección y medidas de protección urgente. Se da cuerpo al mecanismo de protección que corresponde al conjunto de actores y acciones para la protección de periodistas. Se ordena la existencia de un fondo que garantice la puesta en acción de las medidas y se norma la administración del mismo. Se establecen sanciones para quienes incumplan las disposiciones.

Protección a los derechos sociales de los periodistas. Estas leyes se enfocan a la protección de los derechos sociales de los periodistas y sus familias consistentes en acceso a la vivienda, la salud, la educación y capacitación profesional, la cultura y el esparcimiento. Este tipo de protección es particularmente importante para periodistas que se encuentran fuera de los esquemas de seguridad social del Estado como los llamados freelancer o los independientes. Se establecen fondos económicos para garantizar la cobertura y se reglamenta su administración. Se obliga la elaboración de un registro de periodistas beneficiarios.

Protección de derechos civiles para el ejercicio periodístico. Estas leyes sirven para tutelar derechos asociados al ejercicio periodístico y que de esta manera los periodistas puedan invocarlos y hacerlos exigibles en los casos necesarios. Tales derechos, que constituyen prerrogativas del ejercicio de la profesión, son el secreto profesional, la cláusula de conciencia, el acceso a la información y a los actos, y el derecho de autor sobre obras literarias y periodísticas.

A continuación, se desarrollan los resultados del análisis formal de las leyes locales organizados a partir de las tres dimensiones y las 20 categorías fundamentadas de las que se da cuenta en el apartado metodológico: a) protección de los periodistas ante el riesgo, b) organización administrativa para el cumplimiento del objeto de la ley, y c) acciones vinculatorias.

\section{Protección de los Periodistas Ante el Riesgo}

En este apartado, se considera el riesgo de manera amplia, lo cual implica que el objetivo de los tres tipos de leyes es el de minimizar algún tipo de riesgo para los periodistas. Así pues, se establecen mandatos para otorgar certidumbre en su desarrollo social y de las familias, para proteger los derechos civiles asociados a las libertades de expresión y de prensa, y finalmente, para proteger su integridad física frente a las agresiones directas contra su persona.

Llaman la atención dos aspectos. El primero consiste en la definición de periodistas que las doce leyes contemplan. La identificación de los periodistas está asociada, en la mayoría de los casos, a la actividad remunerada de informar a través de los medios de comunicación; lo cual resulta restrictivo (Ruelas et al., 2019). No ocurre así en algunos estados como Baja California, Querétaro, San Luis Potosí y Tamaulipas, en donde la remuneración no es condición, abriendo así el espectro para incorporar a la categoría a los periodistas que no necesariamente reciben pago.

El segundo se refiere al reconocimiento de la representatividad de los periodistas a través de la colegiación. La totalidad de las legislaciones analizadas asumen que en los órganos de control contemplados para su cumplimiento, los periodistas estarán representados por los directivos de las asociaciones gremiales. Sin embargo, históricamente, no ha habido en México "una colegialidad que dote al campo periodístico de la autonomía que tanto requiere para defenderse" (Márquez, 2015 , p. 25). Esta situación podría debilitar, más que fortalecer, la voz de los periodistas ante los mecanismos legales.

Otro aspecto importante es la falta de explicitación de la censura. El riesgo en el que se encuentran los periodistas está asociado teóricamente a la censura y, como lo indica Waisbord (2002), a la que se relaciona con asuntos políticos. Los ataques contra la prensa significan intentos de intimidación 
por la circulación de la información en la arena pública. Sin embargo, en las leyes revisadas la censura no se menciona como causal de agresiones. La palabra aparece únicamente en el segundo párrafo del artículo 7 de la ley correspondiente al estado de Baja California.

\section{Organización Administrativa para el Cumplimiento del Objeto de la Ley}

Gran parte del contenido de las leyes tiene que ver con la organización administrativa de los órganos, mecanismos y fondos que contemplan, lo cual se interpreta como un indicador de su burocratización. Si bien, es necesario establecer reglas operativas y definir las responsabilidades de los actores, también es cierto que el exceso de burocratización ralentiza la acción protectora. Las leyes más burocráticas son las de protección a las agresiones, en donde las categorías con mayor porcentaje de codificación corresponden a la administración de los mecanismos, la elaboración de diagnósticos para comprobar la validez de la petición de protección y la administración de comités $\mathrm{y}$ de los fondos y fideicomisos.

Esta ha sido una de las grandes críticas a los mecanismos de protección, puesto que los periodistas que lo solicitan están obligados a demostrar su necesidad. Una vez aportadas las pruebas, las legislaciones establecen qué tipo de medidas les corresponden: preventivas, de protección, o de protección urgente. En ese transcurso, el riesgo se vuelve mayor, e incluso existen casos documentados de periodistas que fueron fuertemente agredidos y hasta asesinados mientras se estudiaba su caso (cfr. Ramírez, 2018). Particularmente Veracruz, el estado más preocupante de todos, ha centrado su legislación en normar a la Comisión Estatal para la Atención y Protección a Periodistas, más que a la protección misma. Se trata de una normatividad que se concentra en establecer, únicamente, las reglas administrativas de ese organismo.

En segundo lugar de burocratización aparecen las legislaciones de los derechos sociales, en donde también se prevén órganos y fondos que requieren ser administrados. En estos casos, se contempla la inscripción en un registro de periodistas que serán beneficiarios de los apoyos, lo cual genera suspicacias en un contexto como el mexicano, donde el corporativismo y el clientelismo político han sido la regularidad.

Finalmente, las legislaciones dedicadas a proteger los derechos civiles del ejercicio periodístico son las que menos reglamentan cuestiones administrativas, puesto que están formuladas exclusivamente para tutelar los derechos que los periodistas pueden invocar para proteger la libertad de expresión.

\section{Acciones Vinculatorias}

Es fundamental que las legislaciones establezcan sanciones y acciones vinculatorias que permitan hacer exigibles los derechos, punible su violación y deslindar las responsabilidades correspondientes. Es importante señalar el establecimiento de lazos con otras normatividades que permiten hacer ese deslinde, mayormente las que se refieren a las responsabilidades de los servidores públicos.

Lo anterior permite reconocer un entramado legal en el que las leyes de protección a los periodistas no se encuentran aisladas, sino vinculadas a otras acciones legales. Sin embargo, llama la atención que las formulaciones vinculatorias responsabilizan primordialmente a los funcionarios públicos y a los periodistas. Las responsabilidades de los empresarios de los medios están diluidas y se refieren principalmente a los derechos sociales en los rubros de la capacitación, la seguridad social y las prestaciones laborales. Quedan liberados de la responsabilidad en la protección a las agresiones y violencia. No se reconoce la necesidad de colaboración de la industria mediática, en tanto sector, en esta tarea. 
En contraparte, sí se consideran sanciones para los periodistas que hagan "mal uso" de los mecanismos de protección, así como para los funcionarios públicos. Las sanciones pueden ir desde el retiro de la protección hasta las multas. De manera que los periodistas protegidos cargan con dos pesos, por un lado, el de la violencia directa de la que son objeto, por otro lado, el de la supervisión burocrática mediante protocolos que pueden llegar a ser rígidos y previsibles, lo que pone en riesgo su seguridad. Para los funcionarios, las sanciones se trasladan a la normatividad de la función pública vigente en cada entidad federativa, y a los cuales se les prohíbe, expresamente, que divulguen información reservada.

\section{Evaluación del mecanismo de protección a periodistas}

Con la finalidad de complementar el análisis de las legislaciones locales, se presenta la evaluación que los propios periodistas hacen del funcionamiento de los mecanismos de protección derivados de dichas leyes. Las respuestas de los entrevistados se agrupan en tres tendencias claramente definidas: Las medidas no funcionan, lo hacen a medias, y sí cumplen con su objetivo. De tal suerte, el desarrollo de esta parte del documento se organiza bajo esa misma lógica.

a) Las medidas no funcionan.

La mayor parte de los informantes ( 45 de los 55) coinciden en que los mecanismos institucionales de protección a periodistas no funcionan. Por ejemplo, ECOA3 señala que "se habla mucho acerca de medidas de seguridad, leyes para protegernos, protocolos internacionales, y hasta un fiscal especial; pero en la práctica nada de eso funciona". En ese mismo sentido se expresa EVER5, quien agrega que "el fiscal especial no ha condenado a ningún agresor. Su oficina es como el Muro de las Lamentaciones donde vas a quejarte, pero no pasa nada". EBC7 añade lo siguiente:

Mira, a la Procuraduría General de Justicia del Estado le vale un verdadero cacahuate lo que le sucede a los periodistas. Para empezar, este es un gremio al que no quieren y no les interesa. Los delitos contra la libertad de expresión, derecho a la información, y libertad de prensa no le importan al Gobierno del Estado. Entonces no es una dependencia donde tú vayas y confíes al hacer una denuncia de amenazas. Tienes forzosamente que acudir a organismos internacionales, o a la Fiscalía federal, ante la PGR, para poder hacer tu denuncia, y sabiendo que -al final de cuentas- no sirve absolutamente para nada.

De acuerdo con los entrevistados, esto se debe principalmente a cuatro factores: Falta de resultados, procedimientos inadecuados, colusión entre autoridades y atacantes, y el gobierno es el principal agresor. Por lo que respecta a lo primero, los informantes coinciden en que, a pesar de la existencia de mecanismos para la protección de periodistas, las agresiones no sólo no han disminuido, sino que en algunas regiones incluso se han incrementado. De tal suerte, EVER3 explica que "la única contribución de los mecanismos federales es elevar el costo político para el agresor. Mientras que el programa local también es inútil, porque hace todo menos proveer protección". Asimismo, EJAL5 añade que "se supone que hay una ley que protege a los periodistas, pero no los protege. No les da un chaleco blindado, no les da un seguro de vida. Eso y nada es lo mismo". Por su parte, ESLP1 manifiesta que:

El Gobierno del Estado creó una comisión para la protección de periodistas que no ha funcionado para nada. El Congreso del Estado tiene otra comisión a la que le han llegado 24 casos, de la cuales sólo se han resuelto cuatro, pero no dicen ni cómo ni por qué.

Algunos de los participantes indican que la razón de la ausencia de resultados está asociada con la falta de recursos económicos, materiales, administrativos, y humanos de las dependencias encargadas de la protección a informadores. De ahí que los avances en materia de prevención, atención, y 
combate a los delitos contra los periodistas sean limitados. Las siguientes respuestas ejemplifican la situación:

Sabemos que, para bien o para mal, hay una FEADLE de la PGR. Sabemos que está allí, y que en los últimos años le han reducido los fondos, pero en cuanto a resultados concretos de atención a delitos contra los periodistas se han visto muy pocos. $(E B C 5)$

Supuestamente hay varios mecanismos para la protección de periodistas, pero ninguno funciona realmente. Son como aspirinas para curar el cáncer. Las instituciones oficiales creadas para ese propósito operan con presupuestos muy reducidos, y sólo un pequeño porcentaje de ese dinero se invierte en los reporteros. Lo demás se usa en los gastos operativos como rentas, salarios y eventos. (EVER4)

A la insuficiencia de recursos para operar adecuadamente, se suma la falta de autonomía para que este tipo de dependencias pueda realizar su labor. Ello significa que, al formar parte de los gobiernos federal o estatales, los responsables de velar por la seguridad de los informadores se enfrentan con una serie de obstáculos internos que los llevan frecuentemente a callejones sin salida. Esto es particularmente evidente cuando tienen que investigar agresiones cometidas por las mismas autoridades de gobierno. Un ejemplo ilustrativo lo aporta ESON5:

Si vas a la Comisión Estatal de Derechos Humanos te vas a dar cuenta de que la persona a cargo fue el anterior jefe del Sistema Penitenciario Estatal, cuyo superior es quien está al mando de la Secretaría de Seguridad Pública, quien a su vez recibe órdenes del gobernador. Así es como te das cuenta de que las instituciones autónomas no son en realidad tan autónomas.

En cuanto al segundo factor, varios periodistas explican que los escasos logros de dichos programas son consecuencia de procedimientos inadecuados para enfrentar y resolver el problema de la violencia contra la prensa en México. Es decir, su principal actividad se limita a registrar las agresiones y generar reportes, pero los funcionarios no le dan seguimiento a las denuncias y, por ende, los casos que concluyen con una solución favorable para la víctima son contados. EGTO1 plantea que "muchas veces prefieres no hacer nada, porque pierdes mucho tiempo, y porque sabes que no van a resolver nada. Sabes que no va a pasar de una recomendación al agresor para que no lo vuelva a hacer". Así se manifiestan estos entrevistados:

Los mecanismos de protección a periodistas no funcionan. Si emprendes una acción legal nunca pasa nada. Nadie monitorea tu caso, a menos de que lo hagas público. Sin embargo, al final terminas siendo un mero número, una estadística más. Estás solo. (ECHI2)

Puede parecer hasta ridículo si tú quieres, pero [los mecanismos] solamente son de papel. El Gobierno del Estado siempre te va a decir que hay muchos mecanismos, pero en los hechos no existe nada. Cuando vas a la Comisión de Derechos Humanos solamente te van a levantar el acta, y al final de cuentas solamente le van a dar seguimiento para llevar estadísticas. (EGRO1)

Además de la falta de recursos y procesos adecuados, otra línea de respuestas apunta a que los pobres resultados se explican a partir de la colusión entre agresores y autoridades; lo cual representa el tercer factor. En otras palabras, los entrevistados perciben que quienes atacan frecuentemente a los periodistas pertenecen a grupos poderosos (crimen organizado, empresarios, sindicatos, por mencionar algunos), que tienen vínculos con diferentes áreas de gobierno tanto local, como estatal y federal. Por lo tanto, algunos funcionarios públicos reciben la orden de ignorar o bloquear las denuncias. En otros casos, los servidores alertan a los atacantes de que la víctima inició un proceso legal en su contra. De acuerdo con los hallazgos usados para este este artículo, Tamaulipas resultó ser el caso paradigmático de esta situación:

El mecanismo federal es un mal chiste, honestamente. Cuando un grupo armado entró en la redacción y comenzó a dispararnos como una amenaza ¿Acaso crees que acudimos a la policía? Por supuesto que no, 
porque entonces sí que nos hubieran tirado a matar. El protocolo federal de protección a periodistas es una basura. (ETAM1)

La denuncia ante las autoridades competentes no funciona, porque tú llegas al Ministerio Público a levantar una denuncia y, todavía no te entregan la copia de la misma, cuando ya te están esperando algunas personas afuera para tomar represalias por haber ido a presentar la denuncia. Las autoridades están invadidas en todos los niveles. (ETAM3)

El cuarto factor que impide un adecuado funcionamiento de las medidas encaminadas a la protección de los informadores en México es el más extremo, porque implica que algunas autoridades gubernamentales son quienes atacan a los periodistas. Esto significa que a la lista de los agresores antes señalados se suman también las fuerzas del orden y/o funcionarios de gobierno de manera individual. Por esta razón, varios de los entrevistados han experimentado alguna agresión por parte de algún servidor público o, por lo menos conocen el caso de algún colega que la haya sufrido. Este par de declaraciones pone de manifiesto esta problemática:

Sé que el gobierno del estado creó un comité de protección a periodistas con funcionarios del propio gobierno, y si te ocurre algo, tienes que ir a pedir las medidas preventivas. Estas medidas de protección son desde que si has sido amenazado, se empieza a investigar. También te contactan con [la Comisión Estatal de] Derechos Humanos, y te mandan una patrulla afuera de tu casa. Pero muchas veces las medidas no se cumplen al $100 \%$ por falta de pruebas, porque nada más fue una amenaza. Es una cosa muy enferma, porque si estás recibiendo amenazas por parte de funcionarios del estado, cómo el mismo gobierno estatal te va a proteger de sus propios funcionarios (ESLP4).

El llamado mecanismo de protección a periodistas es inútil. Uno lo piensa dos veces antes de usarlo, porque tienes que ir a la Secretaría de Gobierno y, si tienes suerte, te mandan un guardaespaldas, quien es un policía. Sin embargo, la mayoría de las agresiones provienen de la policía o del propio gobierno. Entonces es como regresar al punto en donde todo empezó. (ESON3)

Independientemente de dónde provenga la agresión, otro aspecto que agrava la precaria seguridad de los informadores es que varios de quienes estaban protegidos por dicho mecanismo han resultado agredidos nuevamente. A este respecto se pronuncia este par de entrevistados:

En términos legales existe el Mecanismo Federal para la Protección de Periodistas y Defensores de Derechos Humanos, pero es un organismo muerto. La ley señala que dicho mecanismo debe existir, lo cual está bien, pero no está funcionando adecuadamente, porque varios colegas que han sido agredidos y hasta asesinados se suponía que estaban protegidos por esta medida. En concreto, existen las medidas legales para protegernos, pero no hay la intención de hacer que funcionen. (ECDMX1)

Existe un área de atención al periodista. Ellos [las autoridades] hablan de un mecanismo de protección a periodistas, hablan de un botón de pánico ¿Me ves con algún botón de pánico? Hablan de una medida donde policías te están vigilando y siguiendo como escoltas ¿Los ves en algún lado? Número de emergencia tampoco lo tienes, pero ellos te comprueban que sí pasaron una bitácora donde tú firmas, y a veces ni tus firmas son. Yo las vi. Efectivamente yo tengo esa medida cautelar, pero cuando fui agredido por un policía ministerial en una escena donde hubo violencia yo estaba dentro de ese programa. Ahorita sigo en ese programa que ellos aseguran, pero entonces cómo he sido agredido y amenazado ¿Qué esperan? Pues que un día no amanezca, o la típica de que me canse de todo y darle carpetazo. Esa es la verdad, no hay más. (ESLP3)

Esta situación se conecta directamente la impunidad. Como se señala al inicio de este artículo, la propia FEADLE reconoce que poco más de uno de cada diez delitos contra los periodistas se resuelve favorablemente para la víctima. Bajo estas condiciones, algunos de los participantes de este estudio señalan que este aspecto impide el funcionamiento adecuado de los mecanismos de protección.

El Gobierno del Estado creó una fiscalía especializada para estos delitos, pero no acudimos porque sabemos que no se va a resolver nada. En realidad, esto que pasa es producto de la corrupción y la impunidad en que vivimos. (EGRO2). 
En caso de una agresión, la primera línea de respuesta debería ser la solidaridad del gremio y la exhibición pública del agresor. Después están los mecanismos institucionales, los cuales, honestamente, son inútiles, porque muchos de los casos terminan en la impunidad. (ECHI3).

Ante la falta de logros en cuanto a la protección de periodistas, los entrevistados también consideran que este tipo de programas e iniciativas son una simulación por parte de las autoridades. Dicho de otra forma, desde el punto de vista de quienes han sufrido -o están en riesgo de sufrir- alguna agresión derivada de su trabajo periodístico, el gobierno se limita a diseñar políticas públicas sin que necesariamente sean funcionales o adecuadas. ECOA2 explica que "a las autoridades gubernamentales les encanta presumir que defienden la libertad de expresión y los derechos humanos, pero son los primeros en violar la ley; por eso es que los mecanismos de protección son una mera simulación". Por su parte, ECDMX3 agrega que "hay mucha simulación por parte de las autoridades, quienes piensan que lo tienen todo resuelto. Siempre dicen 'bueno, ya hemos creado el mecanismo', pero no tienen la intención de hacerlo funcionar".

Como resultado de todo lo anterior, se percibe en las respuestas de los informantes una sensación de desconfianza hacia las autoridades encargadas de velar por su seguridad. Es decir, los escasos avances en cuanto a la protección de los periodistas mexicanos provocados por las limitaciones internas de los programas, la colusión con los agresores, y la impunidad generalizada, causan dudas y preocupaciones entre los afectados. Por ejemplo, ESON2 dice que "tengo muchas dudas sobre la eficiencia de los mecanismos institucionales de protección. Sé que el gobierno tiene algunos protocolos, pero no creo que funcionen". De esa misma manera se expresa ECDMX4: "Creo que por ahí hay áreas específicas de apoyo y protección para periodistas, pero si tú me preguntas cuáles son no me las sé, porque ni siquiera confío en ellas".

b) Las medidas funcionan a medias

La segunda línea de respuestas apunta a que los protocolos de protección a periodistas operan medianamente bien, lo cual fue la opinión de seis participantes de este estudio. Tres son los fundamentos que los entrevistados aportaron para justificar su evaluación: Burocracia excesiva, algunas medidas son efectivas, y la presión externa obliga a las autoridades a dar resultados.

Un par de periodistas (EBC2 y ETAM2) consideran que el principal obstáculo para el funcionamiento del mecanismo de protección a los informadores es el exceso burocracia. La abundancia de trámites ralentiza la toma de decisiones $\mathrm{y}$, como resultado, impide la expedita activación de los protocolos necesarios. En otras palabras, la violencia contra los reporteros implica que las acciones sean tomadas de manera inmediata, pero la dinámica habitual de las oficinas de gobierno no facilita su oportuna aplicación. En muchas ocasiones las dependencias encargadas en estos temas se limitan a registrar los incidentes y pocas veces les dan seguimiento a los casos. Precisamente por ello, los contados logros son -a decir de $E B C 2$ - "llamaradas de petate".

Aunado a lo anterior, EMICH2 argumenta que no todos los actores involucrados en los mecanismos para la protección a periodistas entienden su rol en el proceso y, por lo tanto, desconocen qué deben hacer. Es decir, no existe comunicación ni coordinación entre los elementos que deben velar por la seguridad de los informadores, lo que impide que los resultados de dichos programas se queden a medio camino.

[El mecanismo] funciona a medias. Yo estoy inscrito y justamente lo que pasa es que me piden que use el botón de pánico para que te localicen con GPS, o al menos sepan dónde estás, dónde quedaste. Cuando lo activé lo que me pidieron es que avanzara sobre la carretera donde nos pasó [una agresión]. Como no sabían qué hacer, nos dijeron que avanzáramos sobre la misma carretera y donde encontráramos un policía le pidiéramos su ayuda. Ese es el mecanismo de protección a los periodistas. 
Por su parte, otros dos entrevistados de Baja California ( $E B C 4$ y $E B C 8$ ), explican que algunas medidas cautelares derivadas del mecanismo de protección a informadores sí han sido efectivas. Tal es el caso de la asignación de guardaespaldas y la colocación de cámaras de seguridad en la casa del periodista en riesgo, ambas acciones han logrado disuadir a los agresores. En casos más graves, especialmente cuando hay amenazas abiertas y confirmadas de muerte, se procede a la reubicación de la víctima a otra ciudad.

El tercer argumento que explica por qué los programas encaminados a salvaguardar la seguridad de los periodistas funcionan medianamente apunta a agentes externos. Los restantes dos informantes ( $E B C 1$ y $E C D M X 2)$ opinan que dado que, por sí mismas, las autoridades no pueden o no quieren actuar, es necesaria la intervención de los propios medios de comunicación y/o asociaciones de periodistas, tanto nacionales como internacionales. En el primer caso, explica ECDMX2, el apoyo de la empresa para la que trabaja el agredido es crucial, porque la visibilidad se incrementa y, con ella, la presión al gobierno. Sin embargo, para la mayoría de los reporteros freelance o que trabajan en pequeños medios locales con poco impacto, esto no sucede. Por otra parte, cuando grupos como Artículo 19, Reporteros Sin Fronteras o el Comité para la Protección de Periodistas, ofrecen su apoyo a la víctima, las autoridades activan más fácilmente los protocolos necesarios.

Los mecanismos sí funcionan siempre y cuando haya una presión. Dentro de estos mecanismos está la Ley para la Protección de Periodistas y Defensores de Derechos Humanos, que está siendo regulada por la Secretaría de Gobernación, por la FEADLE, y aparentemente deberían funcionar. Sin embargo, hay periodistas que han sido asesinados con todo y que tienen esos mecanismos implementados. Entonces no hay eficiencia, porque tal pareciese que estos mecanismos se establecieron con el único objetivo de responder a la presión internacional que tenía México sobre la violencia contra los periodistas. Por eso te dan esta atención, pero para poder ellos dar una cifra y poder decir 'sí tenemos tantos periodistas protegidos, y tal'. $(E B C 1)$

\section{c) Las medidas funcionan adecuadamente}

Finalmente, sólo tres informantes (EBC9, ESLP2 y ETAM4) reconocieron que los mecanismos institucionales para la protección de periodistas sí cumplen con su objetivo. Su postura parte dos argumentos principales: El programa se activa sólo si existe intervención externa, y las medidas funcionan únicamente cuando hay una denuncia de por medio. Por lo que respecta al primer punto, $E B C 9$ y ESLP2 coincidieron en que las asociaciones de periodistas son cruciales ante cualquier agresión contra alguno de sus colegas, porque estos grupos pueden ofrecer asesoría legal a la víctima y acompañarla durante todo el proceso. Además de ejercer presión a las autoridades mediante la visibilización del suceso. $E B C 9$ lo resume de la siguiente manera:

Aunque sé que los colegas desconfían y dicen que las fiscalías especializadas no sirven para absolutamente nada, sí generan material, y sí generan información valiosa. Cuando ocurre algo, inmediatamente nos llaman [a las asociaciones de periodistas del estado] para que acompañemos a nuestro compañero.

Por su parte, ETAM4 es enfático al señalar que mientras no exista una denuncia, las autoridades no pueden intervenir. Es decir, la víctima debe acudir a las instancias correspondientes para que su caso pueda ser investigado y, eventualmente, resuelto de manera favorable. De lo contrario, una agresión por sí misma no se va a solucionar y, posiblemente, hasta se repita:

No es protección. No se puede llamar protección como tal, pero por lo menos hay una reacción desde la autoridad ante alguna situación que haya sufrido un periodista; pero el propio periodista lo tiene que denunciar, porque es la parte ofendida. Sin embargo, de ahí a que tengamos alguna seguridad particular, no nada de eso. En los casos que han pasado de alguna agresión verbal a una física contra algún compañero, y lo ha denunciado, sí han venido a investigar. 


\section{Discusión Final}

A pesar de la profusa documentación sobre la violencia contra periodistas en México, y de las acciones que se han llevado a cabo, esta tendencia no ha podido ser revertida. Si bien, la problemática no es exclusiva de este país, puesto que constituye una preocupación global, consideramos que el contexto local donde ocurre requiere ser colocado como una categoría fundamental para investigarla.

En ese sentido, encontramos que la UNESCO (2018) advierte del incremento de la hostilidad contra los comunicadores en todo el orbe; Waisbord (2002), por su parte, apunta que los regímenes postautoritarios latinoamericanos son caldo de cultivo para ello, y Márquez (2015) analiza las condiciones estructurales de México en las que aparece la violencia contra periodistas. En el nivel local, diversos investigadores analizan diferentes dimensiones de la hostilidad contra la prensa en las regiones del país, cuyos trabajos han sido referidos a lo largo de este texto.

Proteger a los periodistas para que ejerzan con seguridad su profesión, beneficia no sólo a los periodistas, sino a toda la comunidad, puesto que como plantea Izquierdo (2012) el periodismo es un elemento indispensable de la sociedad para experimentar una democracia que no se agota en las urnas, sino que se extiende en el ejercicio de las libertades, y una de las principales es la de expresión. Evidentemente, las condiciones adversas a las que los informadores se enfrentan cotidianamente son sólo una muestra de una problemática estructural más compleja que afecta a otros actores sociales en México. Dicho de otra forma, al igual que las mujeres, indígenas o -más recientemente- médicos, el gremio periodístico es un grupo vulnerable que requiere atención específica, dadas las incesantes agresiones de las que son objeto.

Hemos tomado como objeto de estudio para este trabajo las legislaciones locales de protección a periodistas en México y las experiencias que los informadores han tenido al solicitar sus medidas. Su importancia consiste en que, en teoría, constituyen una primera línea del ejercicio del Estado de Derecho, el cual, dentro de una federación, debe ofrecer garantías de protección a los ciudadanos. El índice de la libertad de prensa de PoliLat (2020) nos muestra cómo aún existen entidades en donde esa garantía tiene obstáculos, pero no hay mecanismos para protegerla, ampliando así las brechas ya existentes. El análisis completo nos muestra, sin embargo, que contar con los instrumentos legales no es suficiente para aminorar el problema, por lo que es necesario escuchar a los periodistas para identificar en dónde están las fallas.

Las legislaciones locales que tienen por objeto proteger a los periodistas se distribuyen en por lo menos tres tipos: protección de los derechos sociales, de los derechos civiles y contra la violencia. Sin embargo, sólo dos tercios de las entidades del país reconocen la necesidad de reglamentar al respecto, y en ninguna aparecen los tres tipos de protecciones juntas. Resulta alarmante esa indiferencia de parte del Estado si se toma en cuenta que las cifras colocan a México como el lugar más peligroso del mundo para ejercer el periodismo. En cuanto a la protección de la integridad física de los periodistas, las legislaciones locales correspondientes se alinean con la legislación federal en la materia, reproduciendo una estructura similar a nivel subnacional, con sus aciertos y sus aspectos problemáticos como la alta burocratización en el otorgamiento de las medidas de protección. Respecto a los otros dos tipos de protección, no existen leyes por el estilo a nivel federal, por lo que en esos casos las normatividades locales llevan la delantera.

Las leyes son una forma de reconocimiento de los asuntos significativos para una comunidad jurídica y, asimismo, constituyen un conjunto de pautas mediante las cuales esa comunidad busca resolver sus problemas particulares. Son un modelo normativo que, dicho en términos sociológicos, constituyen un tipo-ideal, por lo tanto, siempre habrá distancia entre la letra de la ley y la realidad. Más aún, cuando esas leyes deben ser aplicadas en un contexto altamente complicado para su observancia por situaciones graves como la corrupción, la colusión de autoridades con el crimen 
organizado, el clientelismo político, la precarización de la profesión periodística, la degradación social y, en general, las condiciones desfavorables por las que atraviesa la sociedad mexicana en la actualidad.

Ese distanciamiento entre la letra de la ley y la realidad es palpable en las experiencias de los periodistas que han solicitado la protección recogidas aquí a través de las entrevistas semiestructuradas: no se actúa de oficio, se les obliga a comprobar la necesidad de ser protegidos, se les somete a procesos burocráticos como condición para protegerlos, se les sanciona si abandonan las medidas de protección -medidas que los periodistas consideran riesgosas al ser rutinarias y predecibles para los perpetradores-. Estas malas prácticas ocasionan que la violencia aumente, en lugar de disminuir. Con ello, nuestro estudio comprueba nuevamente la reiterada desconfianza de los periodistas hacia los mecanismos de protección instalados por el Estado mexicano expresados en cuatro factores específicos: falta de resultados, procedimientos inadecuados, colusión entre autoridades y atacantes, y el gobierno es el principal agresor.

Eso obliga a que permanezcan las acciones alternativas que los periodistas siguen para enfrentar esas vicisitudes: actuar desde la subpolítica (Beck, 2006), en el plano extrainstitucional, fortaleciendo redes informales de autocuidado y autoprotección. Las estructuras que deberían protegerlos -el Estado y las empresas periodísticas- fallan, y queda en riesgo su integridad física y el derecho de toda la sociedad a tener fuentes de información libres, confiables y plurales que alimenten los procesos democráticos necesarios.

Como toda investigación, este trabajo tiene límites que es necesario reconocer. En primer lugar, una muestra limitada y con abordaje cualitativo de periodistas que se expresaron sobre los mecanismos de protección en la mayoría de los estados que cuentan con uno, lo cual no necesariamente arroja resultados generalizables. En el discurso de los participantes, además, se observan traslapes en su valoración de los mecanismos estatal y federal. Otro aspecto es el sesgo de la consideración del riesgo hacia las agresiones físicas en menoscabo de otras formas de violencia estructural como la precarización de la profesión periodística, los controles a través de la publicidad oficial y procesos judiciales contra periodistas, la falta de garantías para la protección de sus fuentes informativas, entre otras cosas.

Estas limitaciones también abren planteamientos para una agenda de investigación futura. Un asunto que podría integrar dicha agenda sería, por ejemplo, aprovechar estos datos exploratorios para elaborar una encuesta que relacione las características de los mecanismos de protección previstos en las leyes con la experiencia de los periodistas en todas las entidades correspondientes. La encuesta se aplicaría a muestras significativas de periodistas por entidad, para hacer generalizables los resultados. Esto podría replicarse, asimismo, en otros países con condiciones similares y avanzar así en la realización de estudios comparados internacionales que permitan situar el problema y poner en contraste los avances y rezagos en esta problemática. Tal información puede apoyar en la toma de decisiones de los Estados para definir políticas públicas adecuadas con relación a la protección de periodistas, lo que significa también, contribuir a mejorar la calidad de la información puesta a disposición de los ciudadanos para su bienestar.

\section{Bibliografía}

Artículo 19 (2019). ARTICLE 19 presenta el informe especial "Protocolo de la Impunidad en Delitos contra Periodistas". https://articulo19.org/informeimpunidad/

Beauregard, L. P. (2020). 2019 se convierte en el año más violento en la historia reciente de México. El País, 1. https://elpais.com/internaciona1/2020/01/21/mexico/1579621707_576405. html 
Beck, U. (2006). La sociedad del riesgo. Paidós.

Blomeier, H., Arias, J., Cardiel, R. H., Belmont, A. G., Fitzmaurice, M., \& Ortega, R. (2019). Índice de desarrollo democrático de México 2018. http://idd-mex.org/2018/

Botero, C. (2013). Violencia contra periodistas y trabajadores de medios: estándares interamericanos y prácticas nacionales sobre prevención, protección y procuración de la justicia. Comisión Interamericana de Derechos Humanos.

Brambila, J. A. (2018). Libertad de expresión. Informe 2018. Avances y tareas pendientes para el fortalecimiento de la libertad de expresión en México. CASEDE.

Calveiro, P. (2012). Violencias de Estado. La guerra antiterrorista y la guerra contra el crimen como medios de control global. Siglo XXI.

Cepeda, D. A. (2017). Periodismo violentado en México. Entre las agresiones, la autocensura y el bajo salario en provincia. Argumentos, 30(85), 39-61.

CNDH. (2019). Informe especial sobre el contexto de violencia que enfrentan las personas que ejercen el periodismo y los medios de comunicación en el estado de Veracruz. https:// www.cndh.org.mx/sites/default/files/documentos/2019-11/Violencia-periodismo-medioscomunicacion.pdf

Committee to Protect Journalists (CPJ). (2020). "Journalists Killed in Mexico Between 2000 and 2020/Motive Confirmed or Unconfirmed”. https://bit.ly/3gr1LSJ

De León, S., Bravo, A., \& Duarte, E. M. (2018). Entre abrazos y golpes... Estrategias subpolíticas de periodistas mexicanos frente al riesgo. Sur Le Journalisme, 7, 114-129.

Del Palacio, C. (Ed.). (2015). Violencia y periodismo regional en México. Juan Pablos.

Del Palacio, C. (2018). Callar o morir en Veracruz. Violencia y medios de comunicación en el sexenio de Javier Duarte (2010-2016). Juan Pablos.

Duarte, É. M. (2016). Violencia contra periodistas en México: Análisis de elementos discursivos en la acción social de la red de periodistas de a pie. Universidad Autónoma de Aguascalientes.

FEADLE. (2019). Informe Estadístico. Fiscalía Especial para la Atención de Delitos cometidos contra la Libertad de Expresión. Actualizado al mes de Septiembre de 2019. https://www.gob.mx/ cms/uploads/attachment/file/499081/ESTADISTICAS_Sep_2019.pdf

Franco, D. (2019). Tecnologías de esperanza. Apropiaciones tecnopolíticas para la búsqueda de personas en México. El caso de Las Rastreadores del Fuerte. Comunicación y Sociedad, e7280, 1-29. https://doi.org/10.32870/cys.v2019i0.7280

Gómez, A. M., \& Ramos-Martín, J. (2014). Legislación y medios comunitarios Análisis comparativo de Bolivia y Venezuela. Palabra Clave, 17(2), 484-516. https://oi.org/10.5294/ pacla.2014.17.2.8

González de Bustamante, C. (2014). Professionalism in flux: journalists' self reflections about their work in nothern Mexico. Horizontes de investigación sobre Estudios de Periodismo.

González, R. A., \& Reyna, V. H. (2019). They don't trust us; they don't care if we're attacked”: Trust and risk perception in Mexican journalism. Communication \& Society, 32(1), 147-160. https://doi.org/10.15581/003.32.1.147-160 
González, R. A. (2020). Mexican Journalism Under Siege. The Impact of Anti-press Violence on Reporters, Newsrooms, and Society. Journalism Practice, https://doi.org/10.1080/17512786.2020 .1729225

Guerrero, M. A. (2016). Democracia y Medios en México: el papel del Periodismo (Primera). Instituto Nacional Electoral. https://www.ine.mx/wp-content/uploads/2019/04/cuaderno_34.pdf

Hernández, M. E. (2016). La frágil circunstancia de los periodistas en Jalisco 2015. En R. Gutiérrez (Ed.), Informe sobre la situación de los derechos humanos. Jalisco 2015 (pp. 69-81). Centro de Justicia para la Paz y el Desarrollo A.C.

Hincapié, S., \& López, J. A. (2018). Violencia contra periodistas y rendición social de cuentas : el caso mexicano. Ciencia Política, 13(26), 127-152. https://doi.org/10.15446/cp.v13n26.70244

Hughes, S., \& Márquez-Ramírez, M. (2017). Examining the practices that Mexican journalists employ to reduce risk in a context of violence. International Journal of Communication, 11(January), 499-521.

Izquierdo, L. (2012). Comunicación glocal. El periodismo local abre una ventana al mundo. Tirant Humanidades.

Kucsko-Stadlmayer, G. (2017). El Concepto de la norma jurídica y sus tipos. Revista de la Facultad de Derecho de México, 55(243), 227-242. https://doi.org/10.22201/ fder.24488933e.2005.243.61391

López, J. A. (2020). Política de la información, las ONG y los medios de comunicación en los conflictos por derechos humanos: un balance. Eleuthera, 22(1), 88-105. https://doi.org/10.17151/ eleu.2020.22.1.6

Márquez, M. (2015). El impacto de la violencia criminal en la cultura periodística posautoritaria: la vulnerabilidad del periodismo regional en México. En Violencia y periodismo regional en México (pp. 15-47). Juan Pablos.

Mellado, P. (2016). La publicidad y el control de los medios en Jalisco. En R. Gutiérrez (Ed.), Informe sobre la situación de los derechos humanos . Jalisco 2015 (pp. 59-68). Centro de Justicia para la Paz y el Desarrollo A.C.

Merchant, D. D. (2017). Censura y manipulación de la información en Baja California Censorship and manipulation of information in Baja California. Sur Le Journalisme, 7, 65-83.

Olvera, A., \& Del Palacio, C. (2017). Acallar las voces, ocultar la verdad. Violencia contra periodistas en Veracruz. Argumentos, 30(85), 17-35.

PoliLat. (s/f). Metodología. Recuperado el 24 de julio de 2020, de https://idd-mex.org/ metodologia/

PoliLat. (2020). Índice de desarrollo democrático de México. http://idd-mex.org/

Ramírez, J. (2018). Sin justicia y sin prevención: seguiremos enterrando colegas. En R. Trejo \& J. Trejo-Quintana (Eds.), Persecusión a periodistas (pp. 237-252). Comisión Nacional de los Derechos Humanos.

Relatoría Especial para la Libertad de Expresión de la Comisión Interamericana de Derechos Humanos. (2019). Informe Anual sobre la libertad de expresión. http://www.oas.org/es/cidh/ expresion/informes/ResumenEjecutivo.pdf 
Relly, J. E., \& González de Bustamante, C. (2014). Silencing Mexico: A Study of Influences on Journalists in the Northern States. International Journal of Press/Politics, 19(1), 108-131. https:// doi.org/10.1177/1940161213509285

Reyna, V. H. (2018). Más allá de la violencia: la incertidumbre laboral en el periodismo mexicano. Sur Le Journalisme, 7(1), 98-113.

Reyna, V. H. (2019). Individualización y riesgo de desempleo en los periódicos del norte de México. Frontera norte, 31(31), 1-20. https://doi.org/10.33679/rfn.v1i1.2047

Ruelas, A. C., Maldonado, L., Rivera, V., Díaz, A., Constanzo, C., \& Finnegan, R. (2019). Informe anual 2018: Ante el silencio, ni borrón ni cuenta nueva. https://articulo19.org/ niborronnicuentanueva/

Ruelas, A. C., Rivera, V., Budd, K., Stroeyer, J., \& Díaz, A. (2018). Democracia simulada. Nada que aplaudir. www.articulo19.org

Salazar, M. G. (2018). Aliados estratégicos y los límites de la censura: el poder de las leyes para silenciar a la prensa. Revista Mexicana de Ciencias Politicas y Sociales, 64(235), 495-522. https://doi.org/10.22201/fcpys.2448492xe.2019.235.62643

Santander, P. (2014). Nuevas leyes de medios en Sudamérica: Enfrentando políticamente la concentración mediática. Convergencia, 21(66), 13-37.

Thompson, J. B. (1998). Idelología y cultura moderna. Universidad Autónoma Metropolitana.

Trejo, R., \& Trejo-Quintana, J. (2018). Persecusión a periodistas. Comisión Nacional de los Derechos Humanos. https://www.cndh.org.mx/sites/default/files/doc/Informes/Especiales/EstudioPeriodistas-2018.pdf

UNESCO. (2018). Sancionar el delito, no la verdad. UNESCO.

Vado, L. O. (2008). La jerarquía de las normas locales. Una lectura crítica de Eduardo García Máynez. Cuestiones Constitucionales, 18, 227-243.

Waisbord, S. (2002). Antipress Violence and the Crisis of the State. Harvard International Journal of Press/Politics, 7(3), 90-109. https://doi.org/10.1177/1081180X0200700306 